\begin{tabular}{|c|c|}
\hline 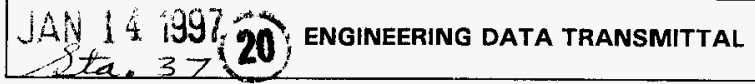 & 1. EDT 618193 \\
\hline
\end{tabular}

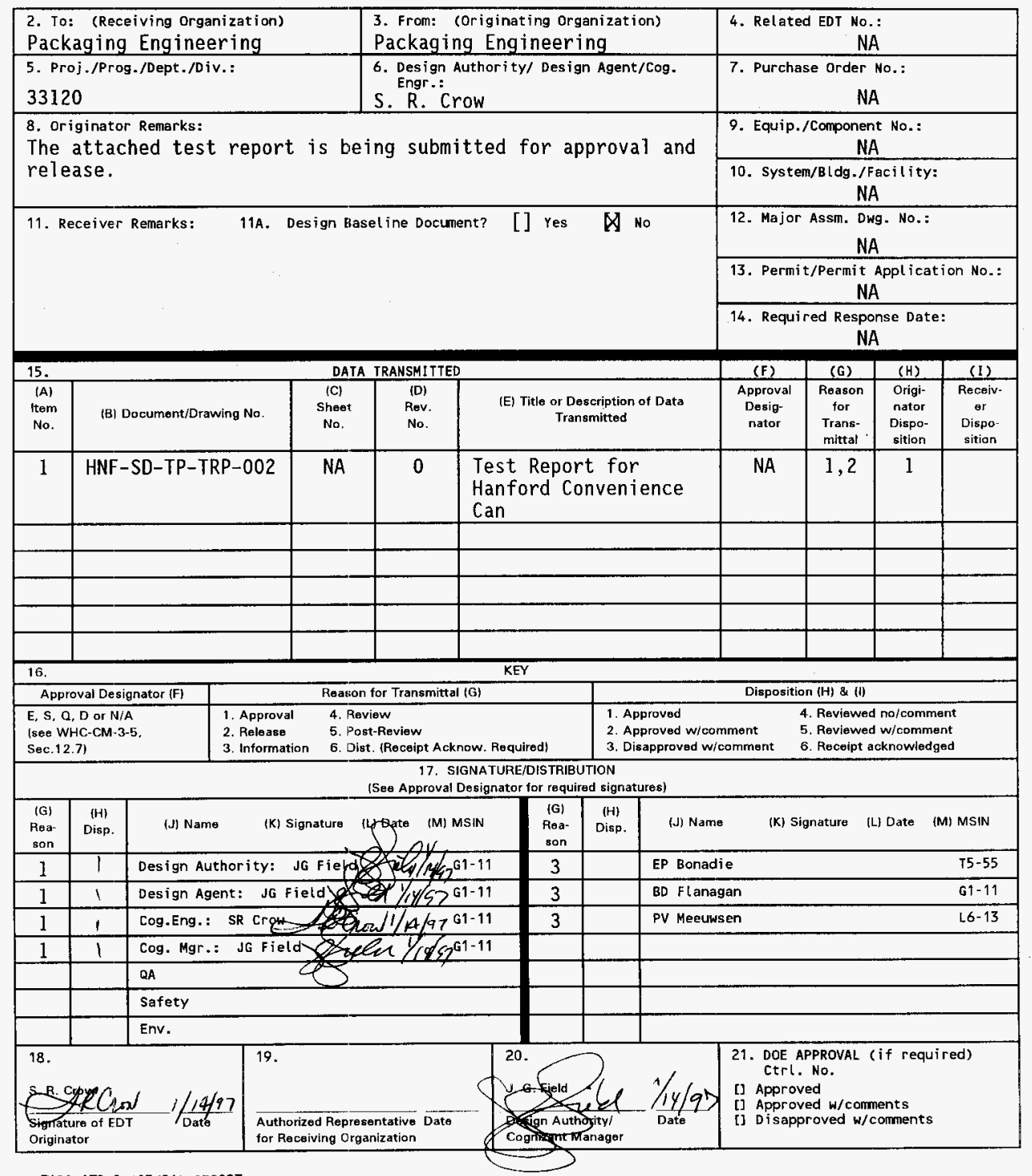

BD-7400-172-2 (05/96) GEF097 


\title{
Test Report for Hanford Convenience Can
}

\author{
S. R. Crow
}

Rust Federal Services Inc. Northwest, Richland, WA 99352

U.S. Department of Energy Contract DE-AC06-87Rt-10930-96RL13200 ps

$\begin{array}{lll}\text { EDT/ECN: } & \text { EDT } 618193 & \text { UC: } 513 \\ \text { Org Code: } & 33120 & \text { Charge Code: } \\ \text { B\&R Code: } & \text { EW7040000 } & \text { Total Pages: } 36\end{array}$

Key Words: Convenience Can, interim storage, plutonium oxide

Abstract: This report provides the test results for the Hanford Convenience Can System. This system consists of four nested sealed steel cans which will be used for the interim storage of plutonium oxide on the Hanford Site. Several of the Convenience Can Systems were loaded with a plutonium oxide simulant and then drop and load tested to ensure that this system would provide adequate containment. The Convenience Can System passed all tests.

TRADEMARK DISCLAIMER. Reference herein to any specific comercial product, process, or service by trade name, trademark, manufacturer, or otherwise, does not necessarily constitute or imply its endorsement, recommendation, or favoring by the United States Government or any agency thereof or its contractors or subcontractors.

Printed in the United States of America. To obtain copies of this document, contact: WHC/BCS Document Control Services, P.0. Box 1970, Mailstop H6-08, Richland WA 99352, Phone (509) 372-2420; Fax (509) 376-4989.

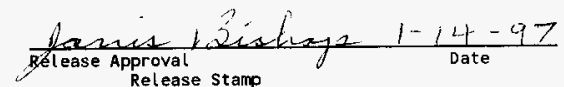

Approved for Public Release 


\title{
TEST REPORT
}

FOR

HANFORD CONVENIENCE CAN

\author{
HNF-SD-TP-TRP-002 \\ REVISION 0
}

January 13,1997

S. R. Crow

Packaging Engineering

Rust Federal Services, Inc. Northwest Operations

Richland, Washington

This report provides the test results for the Hanford Convenience Can system. This system consists of four nested sealed steel cans which will be used for the interim storage of plutonium oxide on the Hanford Site. Several of the Convenience Can Systems were loaded with a plutonium oxide simulant and then drop and load tested to ensure that this system would provide adequate containment. The Convenience Can System passed all tests. 
HNF-SD-TP-TRP-002, Rev. 0

\section{CONTENTS}

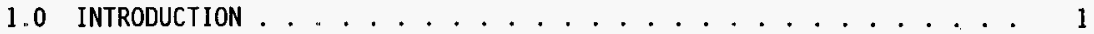

2.0 TEST METHOD AND TEST EQUIPMENT . . . . . . . . . . . . . 2

2.1 TEST ITEM . . . . . . . . . . . . . . . . 2

2.2 DATA . . . . . . . . . . . . . 2

2.2 .1 Tests . . . . . . . . . . . . . . 2

2.2 .2 Acceptance Criteria ............... 2

2.2 .3 Photography ................ . . 3

2.3 INSTRUMENTS AND EQUIPMENT . . . . . . . . . . . 3

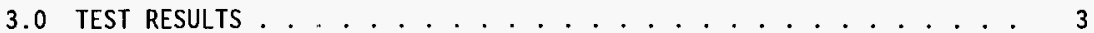

4.0 CONCLUSIONS AND RECOMMENDATIONS ................ . . 4

5.0 DISPOSITION OF TEST ITEM . . . . . . . . . . . . 4

6.0 APPENDIX ........................ 4

\section{LIST OF FIGURES}

Figure 1. Hanford Convenience Can System.

\section{LIST OF TERMS}

$\begin{array}{ll}\mathrm{cm} & \text { centimeter } \\ \mathrm{g} / \mathrm{cc} & \text { grams per cubic centimeter } \\ \text { in. } & \begin{array}{l}\text { inch } \\ \mathrm{kg}\end{array} \\ \mathrm{kilogram}\end{array}$




\section{TEST REPORT FOR THE HANFORD CONVENIENCE CAN}

\subsection{INTRODUCTION}

The Hanford Convenience Can System is to be used for the safe interim storage of plutonium oxide on the Hanford Site. The system consists of four sealed steel cans that are packaged inside each other. There is a convenience can, an inner can, a middle can, and an outer can in the system (see Figure 1).

The testing of the Hanford Convenience Can System was performed by the Hanford Engineering Test Laboratory located in the 300 Area of the Hanford site. The objective of the tests was to show that the system adequately provides containment for the plutonium oxide during storage. The tests simulated conditions that could be encountered during storage and handling such as falling off a shelf onto the floor, falling onto each other, and stacking. All tests were performed using a plutonium oxide simulant and no radioactive materials were involved.

Figure 1. Hanford Convenience Can System

Food Pack Cans with crimped seal lids

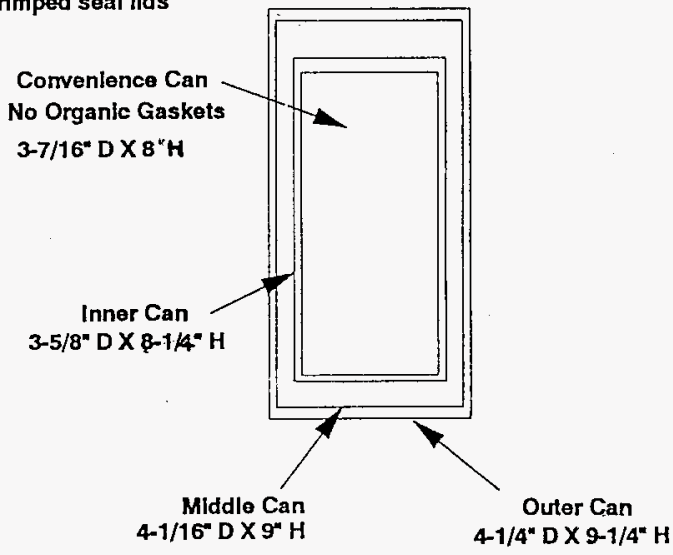

Volume: 1.2 L @ 90\% $65 \%$ of BNFL Conv. Can Capachy Full: $2.6 \mathrm{~kg} \mathrm{Pu}, 2.9 \mathrm{~kg}$ oxlde @ $2.5 \mathrm{~g} / \mathrm{cc}$ or $4.4 \mathrm{~kg}$ Pu, $5.0 \mathrm{~kg}$ oxlde @ $4.3 \mathrm{~g} / \mathrm{cc}$ 
HNF-SD-TP-TRP-002, Rev. 0

\subsection{TEST METHOD AND TEST EQUIPMENT}

\subsection{TEST ITEM}

The test item consisted of Hanford Convenience Can Systems loaded with approximately five kilograms of plutonium oxide simulant. To simulate the payload of plutonium oxide, a mixture of steel grit ( 80 grit), tungsten powder (26 micron), and Magnaglo ${ }^{1}$ was used. The steel grit provided the correct density $(5 \mathrm{~g} / \mathrm{cc})$, the tungsten powder added disperability, and the Magnaglo was used as a leak detection agent.

The systems were loaded and closed in preparation for testing in the same manner as if prepared for actual use. In addition, after sealing, the convenience and inner cans were inspected with ultraviolet light to ensure that they had not been contaminated with the Magnaglo during sealing.

\subsection{DATA}

\subsubsection{Tests}

The drop tests consisted of dropping loaded Convenience Can Systems onto either a hard unyielding surface or onto each other. Complete loaded systems were dropped three times onto a corner and three times horizontally from a height of $213 \mathrm{~cm}$ ( 84 in.) onto a hard unyielding surface. This was to simulate a drop from high storage position onto the floor. In addition, a loaded can with its corner edge down was dropped onto another loaded container from a height of $61 \mathrm{~cm}$ (24 in.). This drop was performed once onto the top and once onto the side of the stationary can. A test was also performed to see the effect of dropping just the two inner cans loaded with simulant onto a corner from a height of 60 inches. This test simulated a drop of the cans during handling before the middle and outer cans have been installed.

The compression test consisted of applying a compressive load equivalent to six times the weight of the package to the test article. This load was placed on top of a loaded Hanford Convenience Can System and held for 24 hours. This was to simulate stacking of the cans which can occur during storage.

\subsubsection{Acceptance Criteria}

The acceptance criteria for the tests was that no trace of the simulated payload could be detected on the outside of the outer can. A visual inspection, which included the use of ultraviolet light to check for the presence of Magnaglo, was performed to ensure that the seal of the inner can was not broken. Failure of the tests would have resulted if the simulated payload or Magnaglo were detected in any location outside of the outer can. The post test inspection included the following steps:

\footnotetext{
1 Magnaglo is a trademark of Magnaflux Corporation
} 


$$
\text { HNF-SD-TP-TRP-002, Rev. } 0
$$

1. The drop area and outer can were checked.

2. The outer can was opened and the middle can was checked.

3. The middle can was opened and the inner can was checked.

4. The inner can was opened and the convenience can was checked.

A visual inspection was made of each container and any deflection of the cans or overall change in the condition of the Hanford Convenience Can System was measured and recorded. Failure of the convenience can (inner most can) did not affect the acceptance criteria.

\subsubsection{Photography}

The Hanford Convenience Can System drop tests were video taped and still photos of damage were taken.

\subsection{INSTRUMENTS AND EQUIPMENT}

All drop tests were performed using the drop pad located in the 305 Building located in the 300 Area of the Hanford Site. Other equipment used in the testing included a crane, a calibrated laboratory scale, an ultraviolet light, photographic and video equipment, and a quick release mechanism for the drops.

\subsection{TEST RESULTS}

All tests passed and there were no unacceptable conditions. With the exception of the convenience cans, no simulant was detected on the outside of any cans during the inspections. The simulant that was detected on the outside of the convenience cans was smeared in locations away from the seams and appeared to be due to cross-contamination during packaging, not due to a breach of the containment. The full results of the tests are shown in the Appendix (Section 6.0) and are summarized below.

Compression Test. Six times the weight of a loaded can $(33.7 \mathrm{~kg}$ ) was applied to the top of a container in the axial direction for 24 hours. There was no sign of deformation and no Magnaglo was detected on the outside of the can.

Corner Drop Tests 1-3. Three different cans were diagonally dropped on the circumferential seam or edge from a height of 84 inches. The cans dented 0.16 to $0.64 \mathrm{~cm}(0.06$ to $0.25 \mathrm{in}$.) at the point of impact. However, the cans did not open and no Magnaglo was detected on the outside of the cans.

Side Drop Tests 4-6. Three different cans were dropped on the longitudinal seam from a height of 84 inches. The cans dented 0.16 to 


$$
\text { HNF-SD-TP-TRP-002, Rev. } 0
$$

$0.32 \mathrm{~cm}(0.06$ to 0.12 in.) at the point of impact. However, the cans did not open and no Magnaglo was detected on the outside of the cans.

Can On Can Drop Test 7. A slightly underweight $(4.5 \mathrm{~kg})$ Convenience Can System was dropped with its corner edge down onto the 1 id of a loaded can from a height which gave the energy equivalent to a fully loaded $(5.5 \mathrm{~kg})$ can being dropped from a height of $61 \mathrm{~cm}(24 \mathrm{in.})$. The impacted can dented $0.64 \mathrm{~cm}(0.25 \mathrm{in.})$ at the point of impact. However, the can did not open and no Magnaglo was detected on the outside of the can.

Can On Can Drop Test 8 . A slightly underweight $(4.5 \mathrm{~kg})$ Convenience Can System was dropped with its corner edge down onto the side of a loaded can from a height which gave the energy equivalent to a fully loaded (5.5 $\mathrm{kg}$ ) can being dropped from a height of $61 \mathrm{~cm}(24 \mathrm{in}$.). The impacted can dented $3.6 \mathrm{~cm}(1.4 \mathrm{in.})$ at the point of impact. However, the can did not open and no Magnaglo was detected on the outside of the can.

Drop Test of Inner Two Cans. One set of two inner cans was dropped diagonally on a circumferential seam or edge from a height of $152 \mathrm{~cm}(60$ in.). The can dented $0.64 \mathrm{~cm}(0.25 \mathrm{in.})$ at the point of impact.

However, the can did not open and no Magnaglo was detected on the outside of the can.

\subsection{CONCLUSIONS AND RECOMMENDATIONS}

Based on the acceptance criteria provided, the Hanford Convenience Can System adequately provides containment for the plutonium oxide during conditions that may be encountered during storage and handling. It should be noted that during testing extreme care was taken to ensure that the cans were not cross contaminated. This same type of care should be used when packaging the actual payload.

\subsection{DISPOSITION OF TEST ITEM}

Testing of the Hanford Convenience Can System is complete. The video tapes and still photos have been forwarded to the cognizant engineer at the Plutonium Finishing Plant. The test items will be disposed of in accordance with disposal procedures used at the Engineering Test Laboratory.

\subsection{APPENDIX}


HNF-SD-TP-TRP-002, Rev. 0

\subsection{COMPRESSION TEST PROCEDURE}

\subsubsection{Pre-Test Activities}

The test engineer shall complete a pre-test checklist provided in Figure 6-1.

Figure 6-1. Pre-Test Procedure for Starting Test Article Compression Test.

\section{Pre-Test Checklist for Starting Test Article} Compression Test.

1. Confirm arrival of Hanford convenience cans (6 items).

2. Hold a pre-test meeting with all personnel involved with this test. The Test Engineer shall review the test procedures and discuss potential hazards involved with this test.

3. Identify safety zones to test personnel and observers.

4. Remove dirt and debris from Test Area.

5. Set up photographic equipment and verify operation.

6. Visually inspect Hanford convenience cans, six items, for any damage. Note any marks which could mistakenly be listed as damage after test. NONE

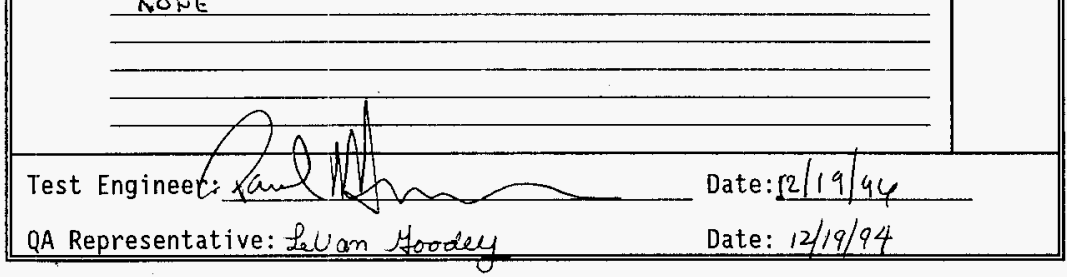




\subsubsection{Compression Test}

The compression test is applied at the top of the container in the axial direction. The container must be subjected, for a period of 24 hours, to a compressive load applied uniformly to the top and bottom of the container in the position in which the container would normally be transported. The compressive load must be the equivalent of five) tiges the weight of the container. $51 x^{50,3919-96}$

6.1.2.1. Perform the pre-test procedure and complete the checklist for the compression test provided in Figure 6-1 and Figure 6-2.

6.1.2.2. Verify cameras are ready.

6.1.2.3. Verify the test article is in a stable position within the test area.

6.1.2.4. Authorize the testing personnel to begin test and start the 24 hour clock. Time: $13: 15 \quad 12-19: 96$

6.1.2.5. Note the time when weight is removed from test article. Time: $13=15 \quad 12-20-96$

6.1.2.6. Following the 24 hour time period, the test engineer, cognizant engineer, and QA representative shall complete the post-test checklist in Figure 6-3. 
Figure 6-2. Checklist for Compression Test.

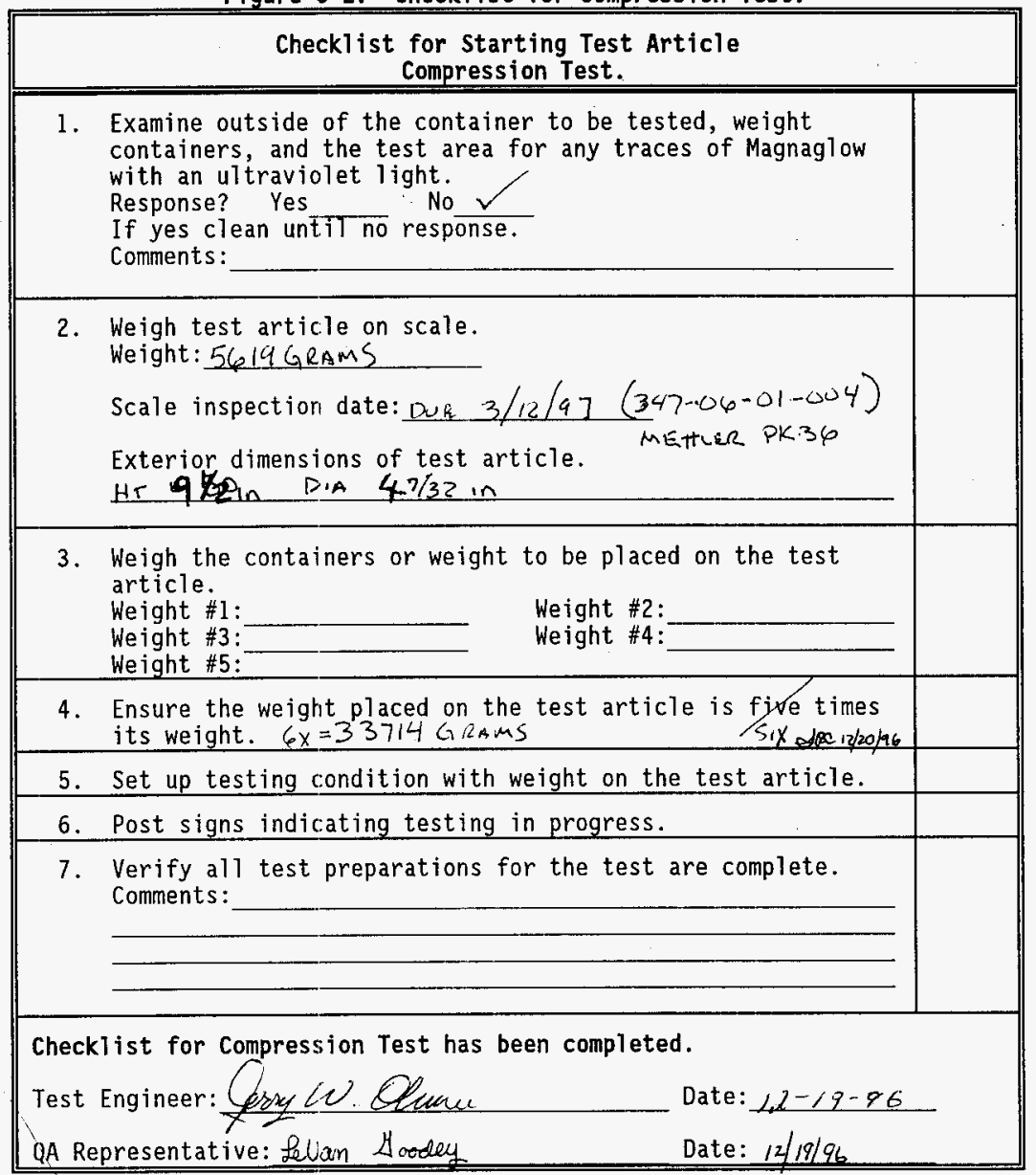


Figure 6-3. Post-Test Checklist for Compression Test.

Post-Test Checklist for Compression Test.

1. Examine the exterior of the container and test area for evidence of Magnaglow with the ultraviolet light.

Response? Yes

No

Comments:

2. Examine the exterior of the container for signs of deformation.

Comments/Measurements:

NONE

3. If there are no signs of deformation then it can be assumed the Hanford convenience can system passed the compression test requirements without the need for an internal inspection. Response?

Agree
Disagree

4. If the answer for step three is disagree, then the container shall be taken apart one can at a time to perform a Magnaglow inspection for each layer by following steps 5 through 7 .

5. Remove the outer can by using the can opener on one end and pulling out the remaining cans. Use the ultraviolet light for evidence of Magnaglow.

Response? Yes No Comments/Measurements:

6. Remove the middle can by using the can opener on one end and pulling out the remaining cans. Use the ultraviolet light for evidence of Magnaglow. Response? Yes No Comments/Measurements:

7. The container passed the Compression Test. (Section 3.3) Yes No

Checklist for Compression Test has been completed.

Test Engineer: ersy w. Oever

QA Representative: Lelan $M$ oodley

Date: $12-20-96$

Date: $12-20-96$ 
Figure 6-4. Pre-Test Checkl ist for Starting Test Article Drop Tests.

\section{Pre-Test Checklist for Starting Test Article} Drop Tests

1. Confirm arrival of Hanford convenience cans (10 items).

2. Hold a pre-test meeting with all personnel involved with this test. The Test Engineer shall review the test procedures and discuss potential hazards involved with this test.

3. Identify safety zones to test personnel and observers.

4. Remove dirt and debris from Test Pad.

5. Set up photographic equipment and verify operation.

6. Inspect and verify all lifting equipment is currently certified.

7. Visually inspect Hanford convenience cans, ten items, for any damage. Note any marks which could mistakenly be listed as damage after drop.

The Pre-Test Checklist has been completed.

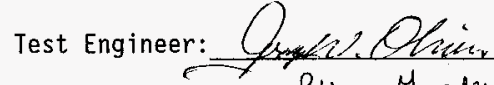
Date: $12-19-96$ QA Representative: Levan Moodey Date: $12 / 19 / 96$ 
HNF-SD-TP-TRP-002, Rev. 0

\subsubsection{Drop Test \#1}

Drop number 1 is the corner drop. The package must strike the target diagonally on the circumferential seam or edge. The convenience can system should be oriented so that the line of impact on the circumferential seam through the center of gravity $(\mathrm{cg})$ is perpendicular to the floor when released. The package shall be raised $X X X$ in. (XXX $\mathrm{cm})$ above the target.

6.2.2.1 Perform pre-drop test activities and complete checklist for drops (see Figure 6-4 and 6-5).

6.2.2.2 Direct all personnel to go to their assigned, safety-approved, observation and test locations.

6.2.2.3 Authorize the rigging crew to $1 \mathrm{ift}$ the test article to an elevation of $X X X$ in. $(X X X \mathrm{~cm})$, and verify that the test article is in the correct orientation and is stable.

6.2.2.4 Verify test article elevation using chain marker taped to package.

$$
\text { Elevation }=8 \underline{4}^{\prime \prime} \quad \text { QA Initial LKG }
$$

Remove chain marker before drop.

\subsubsection{Verify cameras are operating.}

6.2.2.6 Authorize the rigging crew to drop the test article on the test engineers signal.

6.2.2.7 Verify the test article is in a stable position on the test pad before proceeding to the next step.

6.2.2.8 The test engineer, cognizant engineer, and QA representative shall complete the post-drop checklist (see Figure 6-6). 
Figure 6-5. Pre-Drop Checkl ist for Drop Test No. 1.

Pre-Drop Checklist for Drop No. 1

1. Examine outside of the convenience can and test pad for any traces of Magnaglow with an u1traviolet light.

Response? Yes No

If Yes, clean unt $\overline{i l}$ no response.

Comments:

2. Weigh test article on sçale.

Weight: $5623 \mathrm{~g}$

Scale inspection date: $12 / 12 / 96$

3. Move test article onto test pad.

4. Install rigging setup for drop. The package must strike the target diagonally on the circumferential seam or edge.

The convenience can system should be oriented so that the line of impact on the circumferential seam through the center of gravity $(\mathrm{cg})$ is perpendicular to the floor when released.

5. Attach overhead crane hook to rigging and carefully lift the test article until it is just clear of the test pad.

6. Verify all test preparations for the drop are complete.

7. Comments:

Pre-Drop Checklist for Drop No. 1 has been completed.

Test Engineek: tanl Date: 12/19/96

QA Representative: Lellan Hoodly_ Date: 12/19/96 
Figure 6-6. Post-Test Checklist for Drop Test No. 1.

Post-Test Checkl ist for Drop No. 1

1. Examine the exterior of the container and test area for evidence of Magnaglow with the ultraviolet light.

Response? Yes No No $X$

Comments:

2. Record damaged areas with the camera.

3. Examine the exterior of the container for signs of deformation. Comments/Measurements:

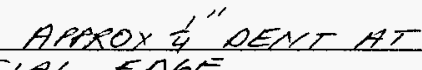
CIFCUMFEREXELQ EDGE

4. Remove the outer can by using the can opener on one end and pulling out the remaining cans. Use the ultraviolet light for evidence of Magnaglow. Response? Yes Comments/Measurements: APKOX $\frac{1}{4}$ DENT AZ

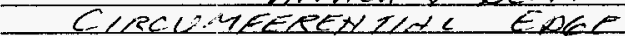

5. Remove the middle can by using the can opener on one end and pulling out the remaining cans. Use the ultraviolet light for evidence of Magnaglow. Response? Yes No Comments/Measurements:

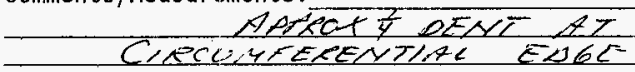

6. The container passed the Drop Test. (Section 3.3) Yes. No

Post-Drop Checklist for Drop No. 1 has been completed. Test Engineer: (enate Date: $10-19-96$ QA Representative: Lelom Locden Date: $12 / 19 / 96$ 
HNF-SD-TP-TRP-002, Rev. 0

\subsubsection{Drop Test \#2}

Drop number 2 is a corner drop. The package must strike the target diagonally on the circumferential seam or edge. The convenience can system should be oriented so that the line of impact on the circumferential seam

- through the center of gravity $(\mathrm{cg})$ is perpendicular to the floor when released. The package shall be raised $X X X$ in. $(X X X \mathrm{~cm})$ above the target.

6.2.3.1 Perform pre-drop test activities and complete checklist for drops (see Figure 6-4 and 6-7).

6.2.3.2 Direct all personnel to go to their assigned, safety-approved, observation and test locations.

6.2.3.3 Authorize the rigging crew to lift the test article to an elevation of $X X X$ in. $(X X X \mathrm{~cm})$, and verify that the test article is in the correct orientation and is stable.

6.2.3.4 Verify test article elevation using chain marker taped to package.

$$
\text { Elevation }=84^{\prime \prime} \quad \text { QA Initial LKE }
$$

Remove chain marker before drop.

6.2.3.5 Verify cameras are operating.

6.2.3.6 Authorize the rigging crew to drop the test article on the test engineers signal.

6.2.3.7 Verify the test article is in a stable position on the test pad before proceeding to the next step.

6.2.3.8 The test engineer, cognizant engineer, and $Q A$ representative shall complete the post-drop checklist (see Figure 6-8). 
Figure 6-7. Pre-Drop Checklist for Drop Test No. 2.

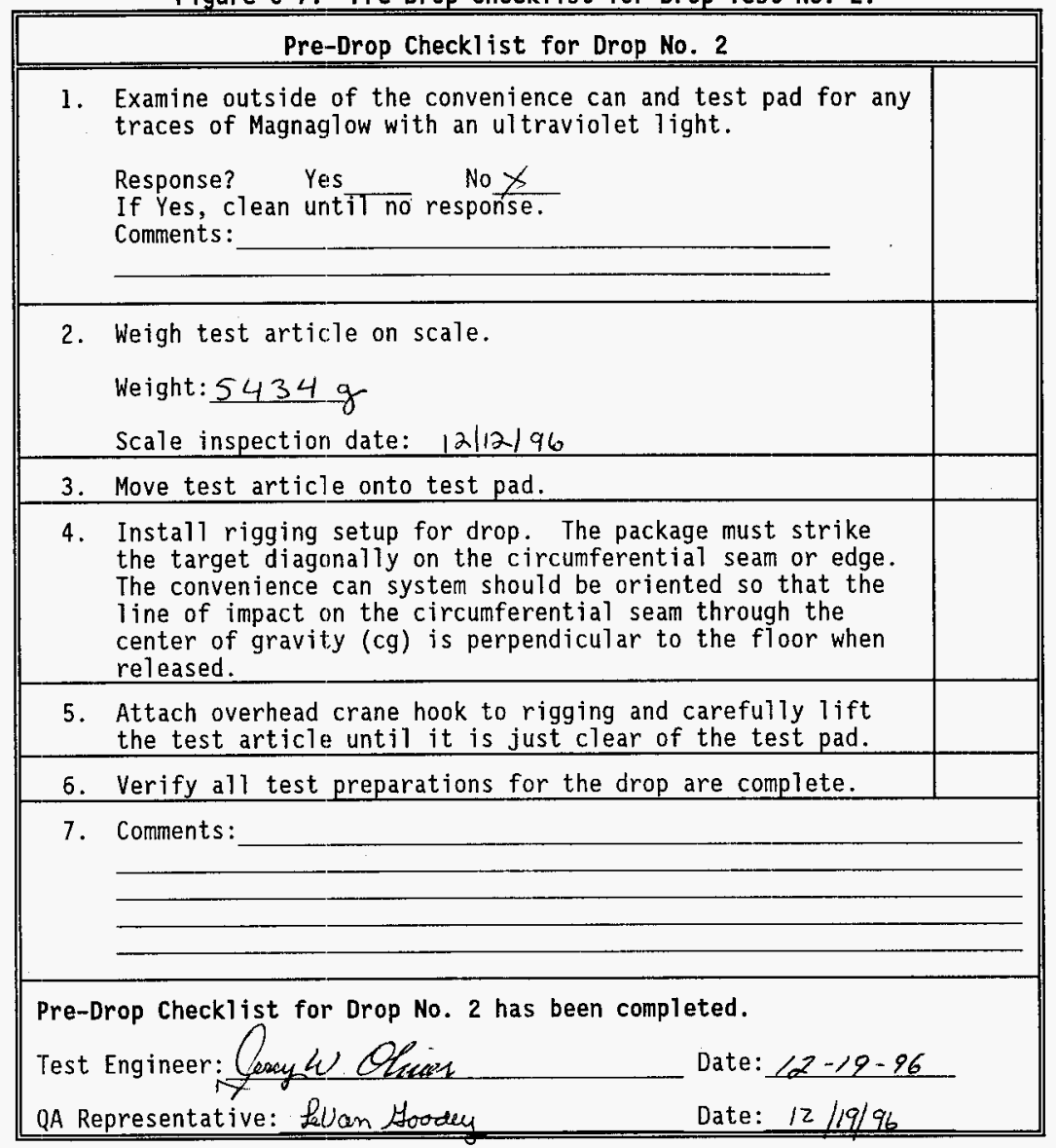


Figure 6-8. Post-Test Checklist for Drop Test No. 2.

Post-Test Checkl ist for Drop No. 2

1. Examine the exterior of the container and test area for evidence of Magnaglow with the ultraviolet light.

Response? Yes

No

Comments:

2. Record damaged areas with the camera.

3. Examine the exterior of the container for signs of deformation.

Comments/Measurements:

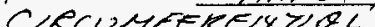

4. Remove the outer can by using the can opener on one end and pulling out the remaining cans. Use the ultraviolet light for evidence of Magnaglow. Response? Yes Comments/Measurements:

No

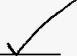

BAPROX 4 DEST AT

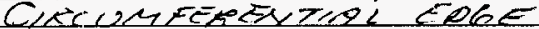

5. Remove the middle can by using the can opener on one end and pulling out the remaining cans. Use the ultraviolet light for evidence of Magnaglow. Response? Yes No Comments/Measurements:

PApor th DENT CUCUMFEPSTML EMET

6. The container passed the Drop Test. (Section 3.3) Yes) No

Post-Drop Checklist for Drop No. 2 has been completed.

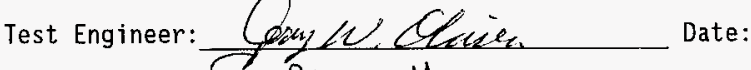
QA Representative: LeVan Hoodey Date: $12 / 19 / 96$ 


\subsubsection{Drop Test \#3}

Drop number 3 is a corner drop. The package must strike the target diagonally on the circumferential seam or edge. The convenience can system should be oriented so that the line of impact on the circumferential seam through the center of gravity $(\mathrm{cg})$ is perpendicular to the floor when released. The package shall be raised $X X X$ in. $(X X X \mathrm{~cm})$ above the target.

6.2.4.1 Perform pre-drop test activities and complete checklist for drops (see Figure 6-4 and 6-9).

6.2.4.2 Direct a]1 personnel to go to their assigned, safety-approved, observation and test locations.

6.2.4.3 Authorize the rigging crew to lift the test article to an elevation of $X X X$ in. $(X X X \mathrm{~cm})$, and verify that the test article is in the correct orientation and is stable.

6.2.4.4 Verify test article elevation using chain marker taped to package.

$$
\text { Elevation }=84^{\prime \prime} \quad \text { QA Initial LKG }
$$

Remove chain marker before drop.

6.2.4.5 Verify cameras are operating.

6.2.4.6 Authorize the rigging crew to drop the test article on the test engineers signal.

6.2.4.7 Verify the test article is in a stable position on the test pad before proceeding to the next step.

6.2.4.8 The test engineer, cognizant engineer, and QA representative shall complete the post-drop checklist (see Figure 6-10). 
Figure 6-9. Pre-Drop Checklist for Drop Test No. 3.

Pre-Drop Checklist for Drop No. 3

1. Examine outside of the convenience can and test pad for any traces of Magnaglow with an ultraviolet light.

Response?
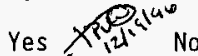

If Yes, clean until no response.

Comments:

2. Weigh test article on scale.

Weight: $5622 \mathrm{~g}$

Scale inspection date: $12 / 12 / 96$

3. Move test article onto test pad.

4. Install rigging setup for drop. The package must strike the target diagonally on the circumferential seam or edge.

The convenience can system should be oriented so that the

line of impact on the circumferential seam through the center of gravity $(\mathrm{cg})$ is perpendicular to the floor when released.

5. Attach overhead crane hook to rigging and carefully lift the test article until it is just clear of the test pad.

6. Verify all test preparations for the drop are complete.

7. Comments:

Pre-Drop Checklist for Drop No. 3 has been completed.

Test Engineer: Qexy W. OChes Date: $12-19-96$

QA Representative: LeVan Hoodey Date: $12-19-96$ 
Figure 6-10. Post-Test Checklist for Drop Test No. 3.

Post-Test Checklist for Drop No. 3

1. Examine the exterior of the container and test area for evidence of Magnaglow with the ultraviolet light.

Response? Yes

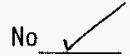

Comments:

2. Record damaged areas with the camera.

3. Examine the exterior of the container for signs of deformation.

Comments/Measurements:

DPPEOX द DEVT AT

CincunteReMTIR ENGE

4. Remove the outer can by using the can opener on one end and pulling out the remaining cans. Use the ultraviolet light for evidence of Magnaglow.

Response? Yes

Comments/Measurements:

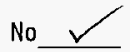

Amoxth bext 94

EIRTUMERTEYTLL CNGE

5. Remove the middle can by using the can opener on one end and pulling out the remaining cans. Use the ultraviolet light for evidence of Magnaglow.
Response?
Yes
No

Comments/Measurements:

AAPOY $\frac{1}{4}$ AEXT HY

CAPUMFEREMTIAC EDGE

6. The container passed the Drop Test. (Section 3.3) Tes No

Post-Drop Checkl ist for Drop No. 3 has been completed.

Test Engineer: Qenclu Qlecie Date: $12-19.96$ QA Representative: LUan Hoodey Date: $12.19-96$ 
HNF-SD-TP-TRP-002, Rev. 0

\subsubsection{Drop Test \#4}

Drop number 4 is a side drop. The package must strike the target on the weakest part not tested by the first drop, the longitudinal seam of the can body. The convenience can system should be oriented so that the line of impact on the longitudinal seam through the center of gravity (cg) is perpendicular to the floor when released. The package shall be raised $x \times x$ in. $(X X X \mathrm{~cm})$ above the target.

6.2.5.1 Perform pre-drop test activities and complete checklist for drops (see Figure 6-4 and 6-11).

6.2.5.2 Direct all personnel to go to their assigned, safety-approved, observation and test locations.

6.2.5.3 Authorize the rigging crew to lift the test article to an elevation of $X X X$ in. $(X X X \mathrm{~cm})$, and verify that the test article is in the correct orientation and is stable.

6.2.5.4 Verify test article elevation using chain marker taped to package.

$$
\text { Elevation }=84^{\prime \prime} \quad Q A \text { Initial } \angle K G
$$

Remove chain marker before drop.

6.2.5.5 Verify cameras are operating.

6.2.5.6 Authorize the rigging crew to drop the test article on the test engineers signal.

6.2.5.7 Verify the test article is in a stable position on the test pad before proceeding to the next step.

6.2.5.8 The test engineer, cognizant engineer, and QA representative shall complete the post-drop checklist (see Figure 6-12). 
Figure 6-11. Pre-Drop Checkl ist for Drop Test No. 4. Pre-Drop Checklist for Drop No. 4

1. Examine outside of the convenience can and test pad for any traces of Magnaglow with an ultraviolet light.

Response? Yes

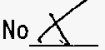

If Yes, clean unt $\pi$ no response.

Comments:

2. Weigh test article on scale.

Weight: $5616 \mathrm{~g}$

Scale inspection date: $12 / 12 / 96$

3. Move test article onto test pad.

4. Install rigging setup for drop. The package must strike the target on the weakest part, the longitudinal seam of the can body. The convenience can system should be oriented so that the line of impact on the longitudinal seam through the center of gravity $(\mathrm{cg})$ is perpendicular to the floor when released.

5. Attach overhead crane hook to rigging and carefully lift the test article until it is just clear of the test pad.

6. Verify all test preparations for the drop are complete.

7. Comments:

Pre-Drop Checklist for Drop No. 4 has been completed.

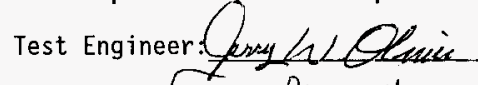

QA Representative: Lelion Loodu

Date: $12-19+96$

Date: $12 /-19 / 96$ 
Figure 6-12. Post-Test Checkl ist for Drop Test No. 4. Post-Test Checklist for Drop No. 4

1. Examine the exterior of the container and test area for evidence of Magnaglow with the ultraviolet light.

Response? Yes

No

Comments:

2. Record damaged areas with the camera.

3. Examine the exterior of the container for signs of deformation.

Comments/Measurements:

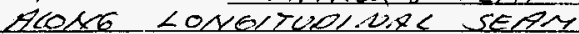

4. Remove the outer can by using the can opener on one end and pulling out the remaining cans. Use the ultraviolet light for evidence of Magnaglow.

Response? Yes Comments/Measurements:

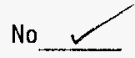

peecor \&" FLAT ROAC

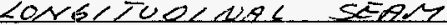

5. Remove the middle can by using the can opener on one end and pulling out the remaining cans. Use the ultraviolet light for evidence of Magnaglow. Response? Yes No Comments/Measurements:

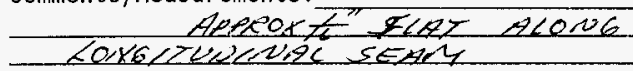

6. The container passed the Drop Test. (Section 3.3) Yes No

Post-Drop Checklist for Drop No. 4 has been completed. QA Representative: LeVan Á Date: Date: $12 / 19 / 96$ 
HNF-SD-TP-TRP-002, Rev. 0

\subsubsection{Drop Test \#5}

Drop number 5 is a side drop. The package must strike the target on the weakest part not tested by the first drop, the longitudinal seam of the can body. The convenience can system should be oriented so that the line of impact on the longitudinal seam through the center of gravity $(\mathrm{cg})$ is perpendicular to the floor when released. The package shall be raised $X X X$ in. $(X X X \mathrm{~cm})$ above the target.

6.2.6.1 Perform pre-drop test activities and complete checklist for drops (see Figure 6-4 and 6-13).

6.2.6.2 Direct all personnel to go to their assigned, safety-approved, observation and test locations.

6.2.6.3 Authorize the rigging crew to lift the test article to an elevation of $X X X$ in. $(X X X \mathrm{~cm})$, and verify that the test article is in the correct orientation and is stable.

6.2.6.4 Verify test article elevation using chain marker taped to package.

$$
\text { Elevation }=8 \zeta^{\prime \prime} \quad \text { QA Initial LKG }
$$

Remove chain marker before drop.

6.2.6.5 Verify cameras are operating.

6.2.6.6 Authorize the rigging crew to drop the test article on the test engineers signal.

6.2.6.7 Verify the test article is in a stable position on the test pad before proceeding to the next step.

6.2.6.8 The test engineer, cognizant engineer, and $Q A$ representative shall complete the post-drop checklist (see Figure 6-14). 
Figure 6-11. Pre-Drop Checklist for Drop Test No. 5.

Pre-Drop Checklist for Drop No. 5

1. Examine outside of the convenience can and test pad for any traces of Magnaglow with an ultraviolet light.

Response? Yes No -

If Yes, clean unt il no response.

Comments:

2. Weigh test article on scale.

Weight: 5434.9

Sca7e inspection date: $12 / 12 / 96$

3. Move test article onto test pad.

4. Install rigging setup for drop. The package must strike the target on the weakest part, the longitudinal seam of the can body. The convenience can system should be oriented so that the line of impact on the longitudinal seam through the center of gravity $(\mathrm{cg})$ is perpendicular to the floor when released.

5. Attach overhead crane hook to rigging and carefully lift the test article until it is just clear of the test pad.

6. Verify all test preparations for the drop are complete.

7. Comments:

Pre-Drop Checklist for Drop No. 5 has been completed.

Test Engineer: Omol Qtues Date: $12-19-96$ QA Representative: Lollan Hoodus Date: $12 / 19 / 96$ 
Figure 6-12. Post-Test Checklist for Drop Test No. 5.

Post-Test Checklist for Drop No. 5

1. Examine the exterior of the container and test area for evidence of Magnaglow with the ultraviolet light.

Response? Yes

No

Comments :

2. Record damaged areas with the camera.

3. Examine the exterior of the container for signs of deformation.

Comments/Measurements: APEOX $\frac{1}{5}$ "ELAT AAONG

LONEITUOLNAC SEAM

4. Remove the outer can by using the can opener on one end and pulling out the remaining cans. Use the ultraviolet light for evidence of Magnaglow.

Response? Yes

No

Comments/Measurements:

AxOX $\frac{1}{5}$ - 141 MLON6

LONGITUNONAL SEMM

5. Remove the middle can by using the can opener on one end and pulling out the remaining cans. Use the ultraviolet light for evidence of Magnaglow.

Response? Yes

Comments/Measurements:

No

APPSOT $\frac{7}{6}$ ELAT RLONG

Lowgrupher sEAr

6. The container passed the Drop Test. (Section 3.3)

Yes

No

Post-Drop Checklist for Drop No. 5 has been completed.

Test Engineer:

Date: $\angle>-19-96$

QA Representative: RUan Hoodey

Date: $12-19-96$ 
HNF-SD-TP-TRP-002, Rev. 0

\subsubsection{Drop Test \#6}

Drop number 6 is a side drop. The package must strike the target on the weakest part not tested by the first drop, the longitudinal seam of the can body. The convenience can system should be oriented so that the line of impact on the longitudinal seam through the center of gravity $(\mathrm{cg})$ is perpendicular to the floor when released. The package shall be raised $X X X$ in. $(X X X \mathrm{~cm})$ above the target.

6.2.7.1 Perform pre-drop test activities and complete checklist for drops (see Figure 6-4 and 6-15).

6.2.7.2 Direct all personnel to go to their assigned, safety-approved, observation and test locations.

6.2.7.3 Authorize the rigging crew to $1 \mathrm{ift}$ the test article to an elevation of $X X X$ in. $(X X X \mathrm{~cm})$, and verify that the test article is in the correct orientation and is stable.

6.2.7.4 Verify test article elevation using chain marker taped to package.

$$
\text { Elevation }=84^{\prime \prime} \quad Q A \text { Initial LKG }
$$

Remove chain marker before drop.

\subsubsection{Verify cameras are operating.}

6.2.7.6 Authorize the rigging crew to drop the test article on the test engineers signal.

6.2.7.7 Verify the test article is in a stable position on the test pad before proceeding to the next step.

6.2.7.8 The test engineer, cognizant engineer, and $Q A$ representative shal1 complete the post-drop checklist (see Figure 6-16). 
Figure 6-11. Pre-Drop Checklist for Drop Test No. 6. Pre-Drop Checklist for Drop No. 6

1. Examine outside of the convenience can and test pad for any traces of Magnaglow with an ultraviolet light.

Response? Yes No

If Yes, clean unt $\overline{11 \text { no }}$ response.

Comments:

2. Weigh test article on scale.

Weight: 54349

Scale inspection date:

3. Move test article onto test pad.

4. Install rigging setup for drop. The package must strike the target on the weakest part, the longitudinal seam of the can body. The convenience can system should be oriented so that the line of impact on the longitudinal seam through the center of gravity $(\mathrm{cg})$ is perpendicular to the floor when released.

5. Attach overhead crane hook to rigging and carefully lift the test article until it is just clear of the test pad.

6. Verify all test preparations for the drop are complete.

7. Comments:

Pre-Drop Checklist for Drop No. 6 has been completed.

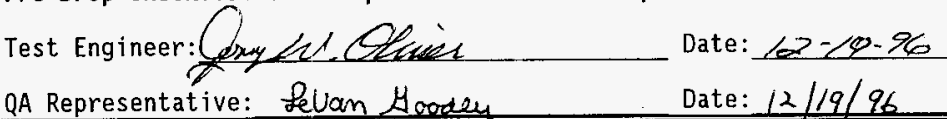


Figure 6-12. Post-Test Checklist for Drop Test No. 6.

Post-Test Checklist for Drop No, 6

1. Examine the exterior of the container and test area for evidence of Magnaglow with the ultraviolet light.

Response? Yes ___ No Comments:

2. Record damaged areas with the camera.

3. Examine the exterior of the container for signs of deformation. Comments/Measurements: Aftar $\frac{1}{8}$ FAAT HLONG LONEITCOCNRL SEA,

4. Remove the outer can by using the can opener on one end and pulling out the remaining cans. Use the ultraviolet light for evidence of Magnaglow.

Response? Yes Comments/Measurements: AAxt $\frac{1}{2}$ " FLAT ALOS 6 LONGITURNAC sEAL

5. Remove the middle can by using the can opener on one end and pulling out the remaining cans. Use the ultraviolet Tight for evidence of Magnaglow. Response? Yes
Comments/Measurements: DAPEO द " FET PLONG LONG/TLNINAL SEARY

6. The container passed the Drop Test. (Section 3.3) Yes No

Post-Drop Checkljst for Drop No. 6 has been completed.

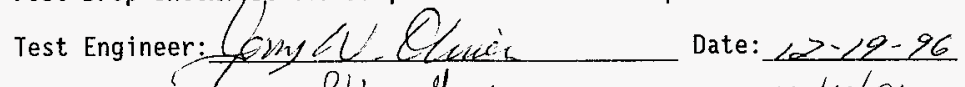
QA Representative: 


$$
\text { HNF-SD-TP-TRP-002, Rev. } 0
$$

\subsubsection{Drop Test \#7}

Drop number 7 is a corner drop onto the top of a loaded convenience can system. The package must strike the top of the target can body. The convenience can system to be dropped should be oriented so that the line of impact on the longitudinal seam through the center of gravity $(\mathrm{cg})$ is perpendicular to the floor when released. The package shall be raised 24 in. $(61 \mathrm{~cm})$ above the target. If the total weight of the dropped package is less than the required 5500 grams, then the drop height shall be adjusted such that a drop energy equivalent is maintained.

6.2.8.1 Perform pre-drop test activities and complete checklist for drops.

6.2.8.2 Direct all personnel to go to their assigned, safety-approved, observation and test locations.

6.2.8.3 Authorize the rigging crew to lift the test article to the appropriate elevation and verify that the test article is in the correct orientation and is stable.

6.2.8.4 Verify test article elevation using chain marker taped to package.

$$
\text { Elevation }=30^{n} \ldots Q \text { Initial } L K G
$$

Remove chain marker before drop.

\subsubsection{Verify cameras are operating.}

6.2.8.6 Authorize the rigging crew to drop the test article on the test engineers signal.

6.2.8.7 Verify the test article is in a stable position on the test pad before proceeding to the next step.

6.2.8.8 The test engineer, cognizant engineer, and QA representative shal1 complete the post-drop checklist. 
Figure 6-13. Pre-Drop Checklist for Drop Test No. 7.

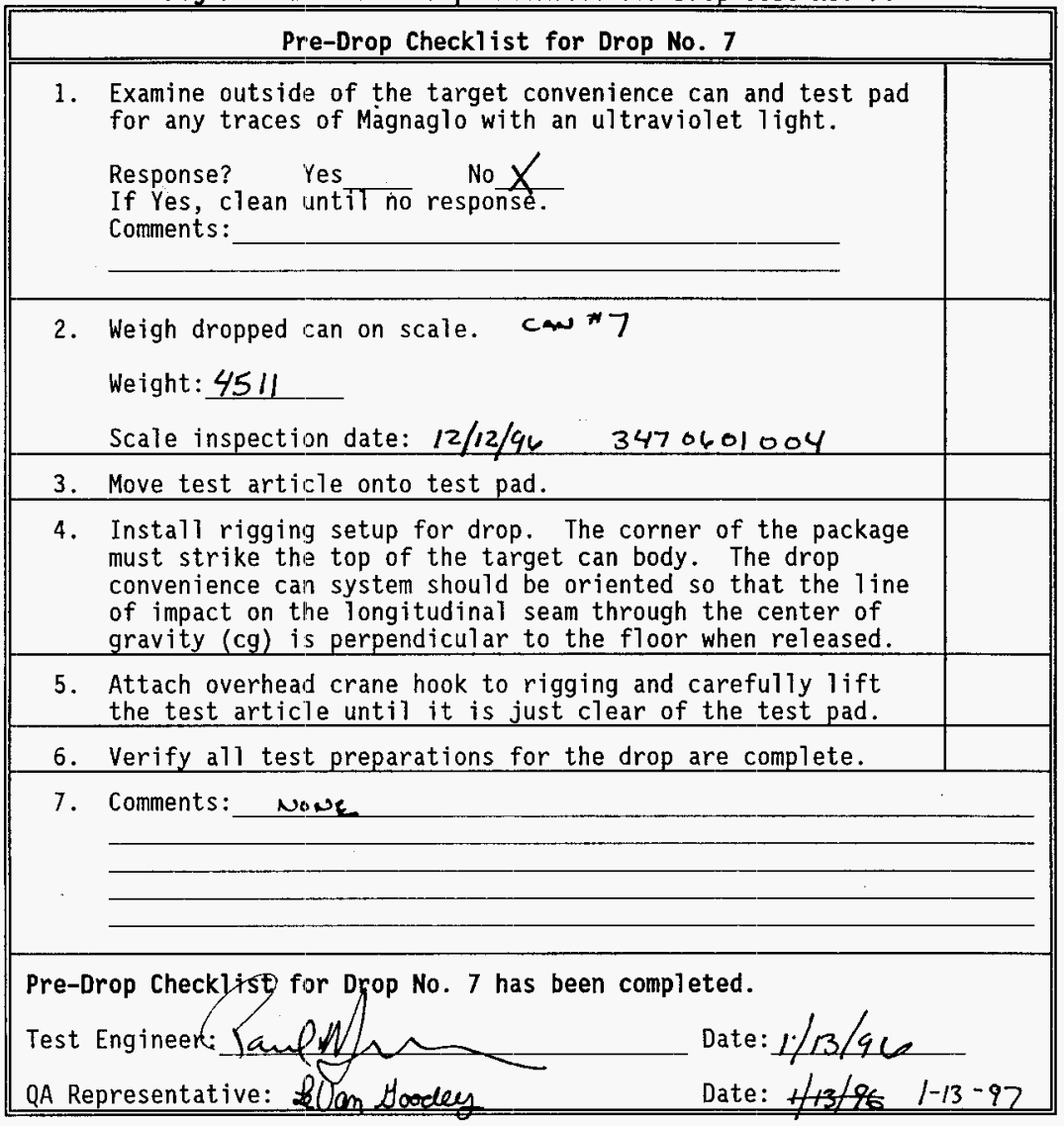


Figure 6-14. Post-Test Checklist for Drop Test No. 7.

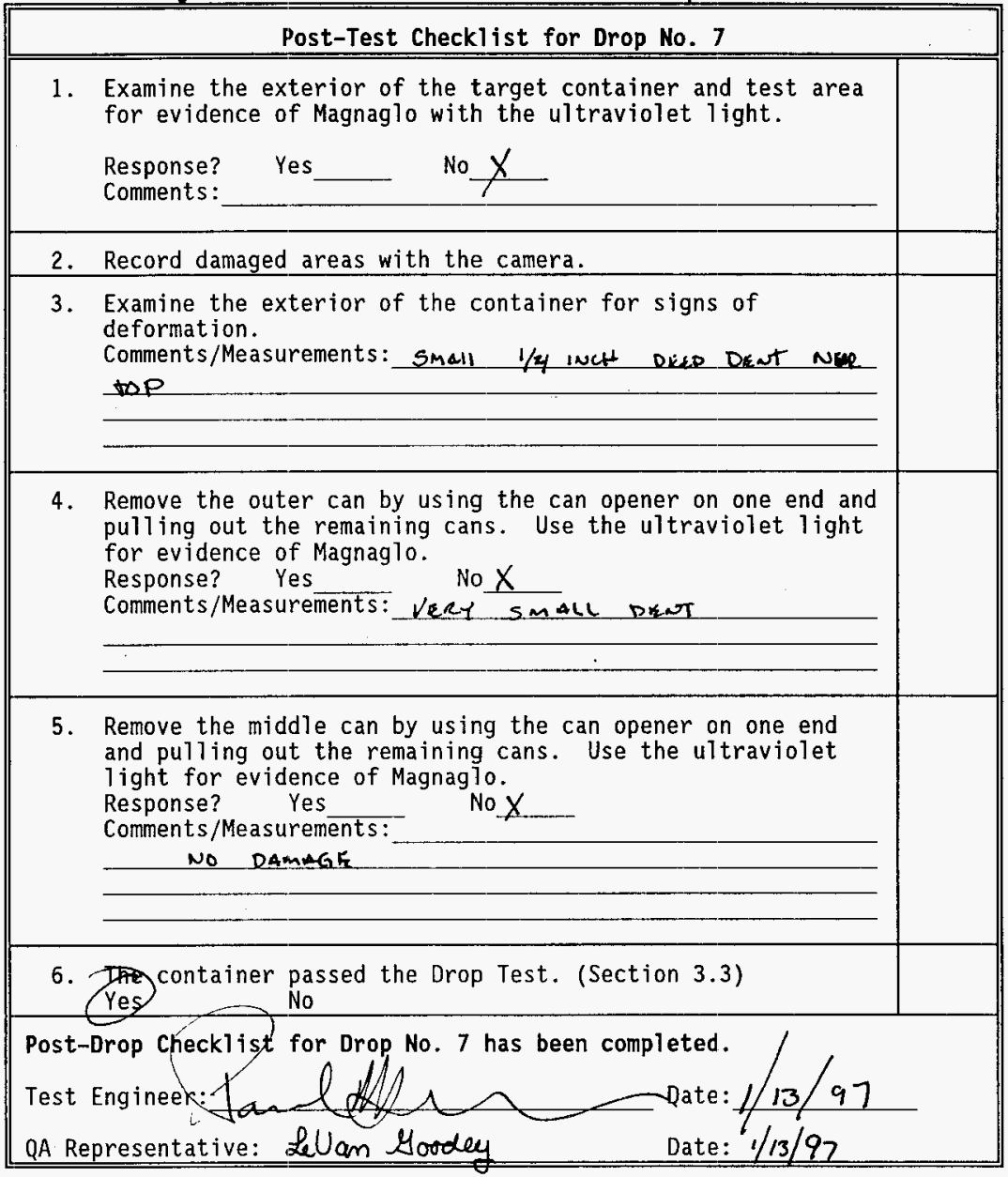




\subsubsection{Drop Test \#8}

Drop number 8 is a corner drop onto the side of a loaded convenience can system. The package must strike the side of the target can body. The drop convenience can system should be oriented so that the line of impact on the longitudinal seam through the center of gravity $(\mathrm{cg})$ is perpendicular to the floor when released. The package shall be raised $24 \mathrm{in}$. $(61 \mathrm{~cm})$ above the target. If the total weight of the dropped package is less than the required 5500 grams, then the drop height shall be adjusted such that a drop energy equivalent is maintained.

6.2.9.1 Perform pre-drop test activities and complete checklist for drops.

6.2.9.2 Direct all personnel to go to their assigned, safety-approved, observation and test locations.

6.2.9.3 Authorize the rigging crew to $1 \mathrm{ift}$ the test article to the appropriate elevation and verify that the test article is in the correct orientation and is stable.

6.2.9.4 Verify test article elevation using chain marker taped to package.

$$
\text { Elevation }=30 \quad \text { QA Initial } \angle K G
$$

Remove chain marker before drop.

\subsubsection{Verify cameras are operating.}

6.2.9.6 Authorize the rigging crew to drop the test article on the test engineers signal.

6.2.9.7 Verify the test article is in a stable position on the test pad before proceeding to the next step.

6.2.9.8 The test engineer, cognizant engineer, and QA representative shall complete the post-drop checklist (see Figure 6-16). 
Figure 6-15. Pre-Drop Checklist for Drop Test No. 8.

Pre-Drop Checklist for Drop No. 8

1. Examine outside of the target convenience can and test pad for any traces of Magnaglo with an ultraviolet light.

Response? Yes No $X$

If Yes, clean unt $\overline{11 \text { no }}$ response.

Comments:

2. Weigh drop test article on scale.

Weight: 4511

Scale inspection date: $12 / \mathrm{n} / 96,347060 / 004$

3. Move test article onto test pad.

4. Install rigging setup for drop. The package must strike the target on the weakest part, the longitudinal seam of the can body. The drop convenience can system should be oriented so that the line of impact on the longitudinal seam through the center of gravity $(\mathrm{cg})$ is perpendicular to the floor when released.

5. Attach overhead crane hook to rigging and carefully iff the test article until it is just clear of the test pad.

6. Verify all test preparations for the drop are complete.

7. Comments:

NONE

Pre-Drop Checklist for Drop No. 8 has been completed.

Test Engineer: bund

QA Representative: LeVon Hoodey

Date: $1 / 13 / 97$

Date: $1 / 15 / 97$ 
Figure 6-16. Post-Test Checklist for Drop Test No. 8. Post-Test Checklist for Drop No. 8

1. Examine the exterior of the target container and test area for evidence of Magnaglo with the ultraviolet light.

Response? Yes Comments:

No $x$

2. Record damaged areas with the camera.

3. Examine the exterior of the target container for signs of deformation.

Comments/Measurements: CaN Sidz CAurd in 13/8 incth

4. Remove the outer can by using the can opener on one end and pulling out the remaining cans. Use the ultraviolet light for evidence of Magnaglo.

Response? Yes

Comments/Measurements:

Amount.

No $x$

CAN SIDE CAUED Small

5. Remove the middle can by using the can opener on one end and pulling out the remaining cans. Use the ultraviolet light for evidence of Magnaglo.

Response? Yes No $x$

Comments/Measurements: CAN SIDE CAMED VERT SMALL Amount

6. The container passed the Drop Test. (Section 3.3) (Yes No

Post-Drop Cheeklist for Drop No. 8 has been completed.

Test Engineerfoud Date:1/13/97

QA Representative: LeUan Noodey

Date: $1 / 13 / 97$ 


\begin{tabular}{|c|c|c|c|c|c|}
\hline \multicolumn{6}{|c|}{ DISTRIBUTION SHEET } \\
\hline \multirow{2}{*}{$\begin{array}{l}\text { To } \\
\text { Distribution }\end{array}$} & \multirow{2}{*}{\multicolumn{3}{|c|}{$\begin{array}{l}\text { From } \\
\text { Packaging Engineering }\end{array}$}} & \multicolumn{2}{|c|}{ Page 1 of 1} \\
\hline & & & & \multicolumn{2}{|c|}{ Date $01 / 14 / 97$} \\
\hline \multirow{2}{*}{\multicolumn{3}{|c|}{$\begin{array}{l}\text { Project Title/Work Order } \\
\text { Test Report for Hanford Convenience Can } \\
\text { (HNF-SD-TP-TRP-002) }\end{array}$}} & & \multicolumn{2}{|c|}{ EDT No. 618193} \\
\hline & & & & \multicolumn{2}{|c|}{ ECN No. NA } \\
\hline Name & MSIN & $\begin{array}{l}\text { Text } \\
\text { With All } \\
\text { Attach. }\end{array}$ & Text Only & $\begin{array}{l}\text { Attach./ } \\
\text { Appendix } \\
\text { Only }\end{array}$ & $\begin{array}{l}\text { EDT/ECN } \\
\text { Only }\end{array}$ \\
\hline $\begin{array}{l}\text { E. P. Bonadie } \\
\text { G. B. Chronister } \\
\text { S. R. Crow } \\
\text { J. G. Field } \\
\text { B. D. Flanagan } \\
\text { M. W. Gibson } \\
\text { D. R. Hekkala } \\
\text { J. M. Held } \\
\text { P. V. Meeuwsen } \\
\text { J. L. Mejia } \\
\text { L. T. Nirider } \\
\text { S. E. Nunn } \\
\text { H. E. Rew, Jr. } \\
\text { R. W. Szempruch } \\
\text { M. D. Talbat } \\
\text { Central Files }\end{array}$ & $\begin{array}{l}\text { T5-55 } \\
\text { T5-09 } \\
\text { G1-11 } \\
\text { G1-11 } \\
\text { G1-11 } \\
\text { T5-55 } \\
\text { T5-57 } \\
\text { T5-11 } \\
\text { L6-13 } \\
\text { T5-08 } \\
\text { T5-53 } \\
\text { T5-11 } \\
\text { T4-15 } \\
\text { T5-48 } \\
\text { T5-15 } \\
\text { A3-88 }\end{array}$ & $\begin{array}{l}x \\
x \\
x \\
x \\
x \\
x \\
x \\
x \\
x \\
x \\
x \\
x \\
x \\
x \\
x \\
x\end{array}$ & & & \\
\hline HNF-SD-TP-TRP-002 File & G1-11 & $x$ & & & \\
\hline
\end{tabular}

